\title{
MULTIPLE EXPOSURES DURING A NOROVIRUS OUTBREAK ON A RIVER-CRUISE SAILING THROUGH EUROPE, 2006
}

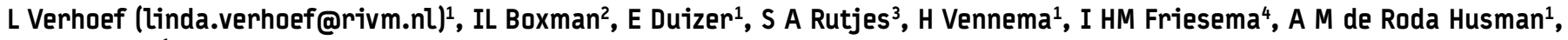 \\ M Koopmans ${ }^{1}$ \\ 1. National institute for Public Health and the Environment, Center for Infectious Disease Control, Diagnostic Laboratory for \\ Infectious Diseases, Bilthoven, the Netherlands \\ 2. Food and Consumer Product Safety Authority, Zutphen, The Netherlands \\ 3. National institute for Public Health and the Environment, Center for Infectious Disease Control, Laboratory for Zoonoses and \\ Environmental Microbiology, Bilthoven, the Netherlands \\ 4. National institute for Public Health and the Environment, Center for Infectious Disease Control, Epidemiology and \\ Surveillance Unit, Bilthoven, the Netherlands
}

\begin{abstract}
In the summer of 2006, several cruise-related viral gastroenteritis outbreaks were reported in Europe. One report came from a river-cruise, belonging to a ship-owner who had two other ships with outbreaks. This situation warranted onsite investigation in order to identify a potential common source of infection. A retrospective cohort study was performed among 137 people on board. Epidemiological questionnaire data were analysed using logistic regression. Stool, food, water and surface samples were collected for norovirus detection. Norovirus GGII.4-2006b was responsible for 48 gastroenteritis cases on this ship as confirmed in six patients. Identical norovirus sequences were detected in stool samples, on surfaces and in tap water. Epidemiological and microbiological data indicated multiple exposures contributing to the outbreak. Microbiological results demonstrated person-toperson transmission to be clearly present. Epidemiological results indicated that consuming tap water was a risk factor; however, this could not be concluded definitively on the basis of the available data. A common source for all cruise-related outbreaks was unlikely. The ongoing outbreaks on this ship demonstrated that evidence based guidelines on effective disinfection strategies are needed.
\end{abstract}

\section{Introduction}

Noroviruses are a well known viral cause of acute gastroenteritis (GE) on cruise ships [1,2]. Most norovirus outbreaks on cruise ships are described as being caused by person-to-person transmission. The virus is persistent and eradication is complicated in such closed settings [3]. On 3 July 2006, the National Institute for Public Health and the Environment (RIVM) in the Netherlands was notified of an outbreak of GE with characteristics indicating a viral agent. The outbreak occurred during successive voyages of a river-cruise ship sailing through several European countries. The outbreak was one of a large cluster of cruise-ship-related outbreaks reported in Europe at that time [4-6], all of which had ascribed norovirus as the causative agent. Moreover, it was the third ship from one company reporting ships with outbreaks and one of four ships that was dealing with GE while sailing through the Netherlands. In addition, this notified outbreak had endured consecutive voyages from 11 June 2006, despite sanitation measures, triggering questions about a possible and persisting common cruise-ship-related source of infection other than person-to-person transmission. An investigation by an outbreak investigation team was initiated to identify a possible source of infection. The ship docked in Nijmegen in the Netherlands on 6
July 2006, and provided the opportunity to undertake an onsite investigation.

\section{Methods}

A retrospective cohort study was performed among passengers and crew joining the second of three successive voyages, being further referred to as the current voyage, of this ship affected by outbreaks of GE. The outbreak investigation team included two epidemiologists from the National Institute for Public Health and the Environment (RIVM) and an inspector from the Food and Consumer Product Safety Authority (VWA). This team interviewed the ship's captain and hotel manager, following a structured questionnaire that focussed on the origin of viral GE outbreaks. Information concerning cleaning procedures was collected. Passengers and crew, joining the ship's current voyage affected by GE, were provided with a questionnaire that they completed individually. Stool, food and drinking water samples together with surface swabs were collected.

\section{Epidemiological data-collection}

The starting date, the menu cycle and information of facilities on board during the current voyage were used to prepare a questionnaire. The questionnaire is available from the authors by request. All food items from the menu served between boarding time on 25 June 2006 and breakfast on 27 June 2006 were included, considering an incubation period of 12-72 hours of the first reported symptomatic person. The following additional risk factors were addressed: water use, public toilet use and contact with infected people. To assess the potential introduction of the virus by a person, history of GE during the week preceding the cruise trip was asked. To allow the grouping of respondents with respect to biological plausible risk from food consumption according to the incubation period, the exact starting and ending time of symptoms were collected.

To determine the potential initial introduction of the causative agent through a person, the person who was the first to report symptoms was contacted. This occurred during the previous and first voyage of this ship affected by GE. This person - the index case - was interviewed by telephone using a questionnaire adjusted to the menu during his voyage. 


\section{Virological data collection \\ Stool samples}

Twenty packages for the collection of stool samples, together with a detailed instruction form, were left on board the ship with the people responsible for passenger health. Stool samples were sent to the RIVM by overnight mail and then stored at $4^{\circ} \mathrm{C}$. This is a commonly accepted procedure for the stable norovirus; furthermore, it increases the response rate for stool sample collection [7]. Crew members were instructed to approach at least five symptomatic and five asymptomatic people for stool sampling. Stool samples were tested for the presence of norovirus, as this virus was the suspected causative agent causing cruise-related outbreaks of GE in Europe at that time [4-6]. For confirmation of a norovirus outbreak, at least two of five case-originating samples need to be tested positive [8]. Stool samples were analysed as described by Svraka et al. [9]. Genotyping was done by sequence analysis of a fragment of the ribonucleic acid (RNA) dependent RNA polymerase gene, as described previously [10].

\section{Potential source samples}

The VWA collected food, water and surface samples according to a protocol designed to avoid cross-contamination of samples. Before sampling tap water, taps were cleaned with alcohol and contact between tap and sample bottle was avoided. Environmental swabs were analysed using a method which will be described elsewhere (Boxman et al., submitted 2008). Food samples were analysed for the presence of norovirus according to in-house protocols using (nested) real time polymerase chain reaction (PCR) assays $[11,12]$. One of the food samples - raspberries - was also analysed in three other specialised food laboratories in France, Finland and the Netherlands, according to local protocols Water samples of one litre were filtered through a positively charged membrane and detected according to Van den Berg et al [13]

\section{Data analyses}

As in most European countries, in the Netherlands microbiological diagnosis of norovirus is outbreak-based [8] instead of case-based. To identify norovirus patients, we used the following definition for acute GE: at least two episodes of diarrhoea and/or at least two times of vomiting within 24 hours. Discrimination was made between early cases and late cases, to determine biological plausible exposure from food addressed in the questionnaire. Early or late cases were characterised as people in whom illness occurred within or after, respectively, 72 hours after the last breakfast included in the questionnaire, i.e. before or after, respectively, 30 June 2006 10 a.m. To determine biological plausible risk from specific food items, the exact onset of disease was compared to the serving moment of the food item while assuming an incubation period of 12 to 72 hours.

Relative risk was calculated for all questionnaire items. Significant and biological plausible risk factors were analysed using a multiple logistic regression model to determine relevant factors after adjustment for potential confounders. Proportions were compared calculating $\mathrm{p}$-values according to $\mathrm{x} 2$ if numbers were sufficient; Fisher's exact test was applied if cells in cross tables contained five or fewer records. All results are presented including $95 \%$ confidence intervals $(95 \% \mathrm{CI})$. Data were analysed using SAS 9.1 for Windows (SAS Institute Inc., Cary, NC, USA).

\section{Results}

The voyage started on 25 June 2006, and ended on 9 July 2006, while docking in 12 cities in Switzerland, France, Germany, the Netherlands and Belgium (Figure 1).

\section{Epidemiological results}

During the outbreak 33 crew members from Romania $(n=8)$, Slovakia $(n=7)$, Hungary $(n=3)$, Bulgaria $(n=3)$, Croatia $(n=3)$, the Netherlands $(n=3)$, Poland $(n=2)$, Serbia $(n=2)$ and Germany $(n=2)$, and 104 passengers from the United States of America $(n=102)$ and the United Kingdom $(n=2)$ were on board. Of these 137 people at risk, 48 (35\%) met the case definition of acute GE. Questionnaires from 29 (88\%) crew members and 98 (94\%) passengers were returned (Table 1 ). Of these, $2(7 \%)$ crew and 46 (47\%) passengers met our case definition for acute GE, with crew having a significantly lower attack rate $(p<0.001)$. The epidemic curve for the cases showed a clear peak in the number of reported cases on day 4 . The somewhat tailed distribution suggested a

\section{F I G U R E}

Epidemic curve during a second outbreak of norovirus on a cruise ship with the locations of stops, 25 June-9 July 2006

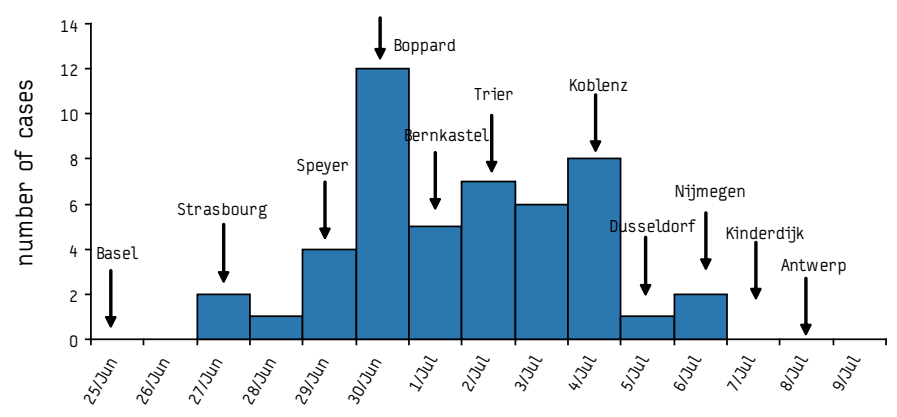

period of the cruise voyage with days of onset of illness

\section{T A B L E 1}

Characteristics and case-definitions of the population at risk during an outbreak of gastroenteritis during a river-cruise

\begin{tabular}{|l|l|l|l|}
\hline Characteristic & $\begin{array}{l}\text { Crew } \\
(\mathrm{n}=31)^{*}\end{array}$ & $\begin{array}{l}\text { Passengers } \\
(\mathrm{n}=98)^{*}\end{array}$ & $\begin{array}{l}\text { Total } \\
(\mathrm{n}=129)^{*}\end{array}$ \\
\hline Mean age (range) & $29.4(20-43)$ & $69.3(14-87)$ & $59.7(14-87)$ \\
\hline Sex male / female & $19 / 12$ & $47 / 50$ & $66 / 62$ \\
\hline $\begin{array}{l}\text { Symptomatic / asymptomatic } \\
\text { people based on }\end{array}$ & & & $48 / 72$ \\
\hline $\begin{array}{l}\text { Case definition for acute } \\
\text { gastroenteritis (AGE) }{ }^{\dagger}\end{array}$ & $2 / 27$ & $46 / 45$ & $11 / 72$ \\
\hline $\begin{array}{l}\text { Case definition AGE and } \\
\text { plausibility food risk }{ }^{\ddagger}\end{array}$ & $1 / 27$ & $10 / 45$ & 42 \\
\hline
\end{tabular}

Questionnaire-data of two crew members and six passengers are missing. At least two episodes of diarrhoea and/or at least two episodes of vomiting within 24 hours.

Food items addressed in the questionnaire a time-span from boarding time through breakfast at 27 June, 2006 If the requested food item was consumed within 12-72 hours before onset of illness, risk from this food item was considered biological plausible. 
secondary wave of cases (Figure 1). Two Romanian crew members who had recently entered the ship during the current voyage reported symptoms of GE the previous week when at home.

Over 100 food items and five behavioural risk factors were addressed in the questionnaire. Of these, possible risk factors for cases in univariate analyses were: contact with a sick room-mate, and consumption of egg, carrot pie, tap water and whipped cream (Table 2). The number of early cases was too low for univariate analysis; however, results indicated tap water, ice cubes, egg consumption and a sick room-mate as possible risk factors. When restricting the plausible exposure from these factors to illness within 72 hours after consumption, the risk from egg, carrot pie and whipped cream consumption was considered unlikely: only eight of 38 ill egg consumers, three of 15 ill carrot pie consumers and two of nine ill whipped cream consumers became ill within 72 hours of consumption of the food item. Raspberries were not a significant risk factor when served as 'raspberry yoghurt'. Raspberries were also used as garnish, but this was not mentioned on the menu and thus not requested in the menu-based questionnaire. Use of public toilets on board could not be a risk factor, since public toilets had been closed a few hours after boarding time. This measure was introduced based on the outbreak during the ship's preceding voyage.

For juice and ice cubes, tap water was needed for preparation. Therefore, juice-drinkers and ice cube users were added to the water consumers in order to account for misclassification. Relative risk from water consumption became 3.2 (1.3-7.8) when combined with ice cube users and 4.2 (1.3-13.5) when combined with juice drinkers, suggesting a potential dose-response relationship. Adding both ice cube users and juice drinkers to the water consumers resulted in a relative risk of $3.3(0.9-12.3)$. In a multiple logistic regression model, the consumption of tap water, ice cubes, orange juice and whipped cream were corrected for person-to-person transmission through the variable 'sick room-mate'. In this model, water - either with or without accounting for misclassification remained a statistically significant risk.

F I G U R E 2

Norovirus strains causing outbreaks of gastroenteritis in Europe in the summer of 2006. Strains were detected in stool, water, food and surface swabs on cruise ships which sailed through the Netherlands. Cruise ship A is the cruise ship investigated in this study. Ship A and $\mathrm{B}$ belonged to the same ship-owner

Pairwise (OG:100\%,UG:0\%) (FAST:2,10) Gapcost:0\% NLV-Polymerase

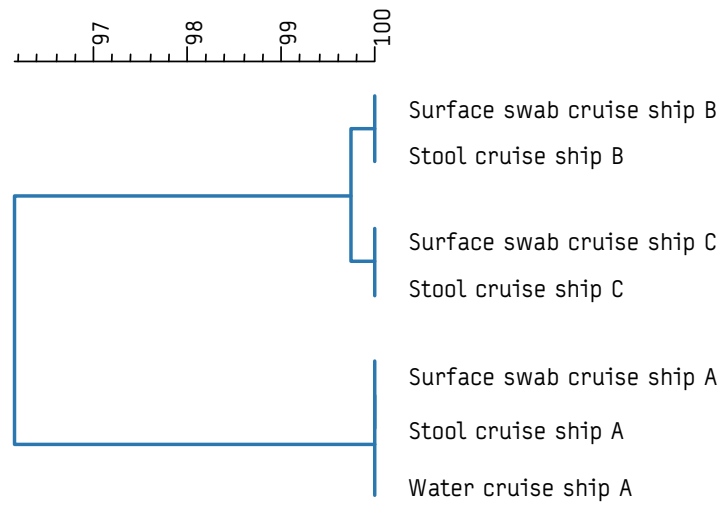

In the outbreak during the previous voyage, 47 of 147 (32\%) people on board presented with symptoms of gastroenteritis. These illness reports were poorly recorded with consequent missing dates of onset, and no attack rates specified for passengers and crew. Reportedly, none of the patients had vomited in a public area on board. A telephone interview with the index case took place at 27 July 2006, which was 6 weeks after the voyage. Since the index patient had noted the details of his illness, he was able to answer the questions quite accurately. The passenger became ill 26 hours after boarding 10 June 2006, which is within the 12-72 hour incubation period. The index patient did not have contact with ill people during the week before boarding the ship. He described having consumed ice cubes, but no tap water or raspberries. This interview was performed before analysis of questionnaire data, but after microbiological testing of collected food and environmental samples.

\section{Virological results \\ Stool samples}

Seventeen stool samples were received and analysed at the RIVM (Table 3). Six of seven stool samples belonging to symptomatic and none of the 10 asymptomatic person stools tested positive for norovirus genotype GGII.4, convincingly assigning this outbreak to norovirus. Sequence analysis confirmed that the outbreak strain was a 2006 b variant, which was not the same as 2006a variant strains detected during the other cruise-ship outbreak from the same company and one other ship sailing through the Netherlands at that time and for which samples were collected for testing by VWA and RIVM (Figure 2) (https://hypocrates.rivm.nl/bnwww/Divine-Event/index.html) [5].

\section{Potential source samples}

Eleven environmental samples were collected during the onsite investigation. Two tap water samples as well as a swab from a door handle and the toilet were taken from a cabin that belonged to a symptomatic crew member. Three swabs were taken from the handle of an alcohol-based hand-disinfection container, the restaurant door and an alcohol-disinfected elevator button. The following food samples were taken: frozen raspberries, frozen mussels, ready-toeat tomato and cucumber salad. In five out of eleven environmental samples GGII norovirus could be detected: one of the tap waters; the toilet; the handle from a disinfection container; the restaurant door; and the raspberries. Except for the raspberries, for which no further typing was possible, in each sample the norovirus was identified as a GGII.4-2006b strain identical in an overlapping sequence of 249 nucleotides to the sequence generated from stool (Figure 2). Three weeks later tap water was re-sampled, in which norovirus could not be detected. The ship's water supply tank included $192.10 \mathrm{~m} 3$. The water quality of the drinking water at docking time in Nijmegen did not exceed the Escherichia coli count based European legislative standards for drinking water.

\section{Measures taken}

No specific guidelines for control of (noro)virus outbreaks were available on board during the initial outbreak. During the previous and initial outbreak (11-25 June 2006) a set of hygiene instructions was acquired from a cleaning company at 15 June 2006. Since then, measures according to this hygiene protocol were taken accurately: public toilets were closed, patients were isolated during their illness, ill crew members disembarked, and hand washing, hygiene and disinfection measures were taken. 


\section{Discussion}

Our combined epidemiological and microbiological results illustrate the difficulties of unravelling sources of infection in cruise ship norovirus outbreaks, and indicated that multiple exposures to norovirus played a role during the outbreak. Contaminated food, water, surfaces and having a sick room-mate may all have contributed to this outbreak. Proof for introduction of the virus via food or water could not be disentangled from the easily and rapidly taking over person-to-person transmission. This is a common problem during ongoing outbreaks in closed settings and may be an important reason why cruise-related outbreaks are mostly assigned to person-to-person transmission. In order to determine whether or not a food-borne source or water-borne source is the cause of an outbreak, the initial and not a successive outbreak should be thoroughly investigated.

Since this ship was one of three ships affected by GE outbreaks and belonging to one owner, a common water- or food-borne source of infection was considered possible. This possibility was strengthened by the fact that the ships partially have the same route, menu cycle and food supplier. Our epidemiological results were based on a high response rate $(93 \%)$ and indicated that contaminated tap water

T A B L E 2

Relative risk $(95 \% \mathrm{CI})$ and biological plausibility for having acquired a norovirus infection on board of a river-cruise ship within the time-span addressed in the questionnaire. Significant risks are presented in bold $(n=120)$

\begin{tabular}{|c|c|c|c|c|}
\hline Risk factor & $\begin{array}{l}\text { All cases } \\
\text { RR(95\%CI) }\end{array}$ & $\begin{array}{l}\text { Early case* } \\
\text { RR(95\%CI) }\end{array}$ & $\begin{array}{l}\text { Late case }{ }^{\dagger} \\
\operatorname{RR}(95 \% \mathrm{CI})\end{array}$ & Plausibility $\ddagger$ \\
\hline Tap water & $2.8(1.4-5.6)$ & $2.6(0.7-7.3)$ & $2.8(1.3-6.0)$ & Yes \\
\hline Ice cube use & $1.7(0.9-3.1)$ & $3.8(0.6-25.4)$ & $1.4(0.7-2.6)$ & Yes \\
\hline Fresh juice & $1.4(0.9-2.1)$ & $2.0(0.7-5.3)$ & $1.1(0.8-1.8)$ & Yes \\
\hline Sick room-mate & $2.2(1.3-3.6)$ & $3.3(0.9-11.7)$ & $1.9(1.1-3.1)$ & Yes \\
\hline egg & $2.9(1.5-5.8)$ & $4.6(0.7-29.5)$ & $2.5(1.3-5.2)$ & No \\
\hline Carrot pie & $1.3(1.0-1.6)$ & $1.2(0.8-1.7)$ & $1.3(1.0-1.7)$ & No \\
\hline Whipped cream & $1.2(1.0-1.4)$ & $1.2(0.9-1.5)$ & $1.2(1.0-1.4)$ & No \\
\hline
\end{tabular}

* Early cases were characterised as people in whom illness occurred within 72 hours after the last breakfast included in the questionnaire, i.e. before 30 June 200610 a.m.

† Late cases were characterised as people in whom illness occurred after 72 hours after the last breakfast included in the questionnaire, i.e. after 30 June 2006 10 a.m.

Food items addressed in the questionnaire a time-span from boarding time through breakfast on 27 June, 2006 If the requested food item was consumed within 12-72 hours before onset of illness, risk from this food item was considered biological plausible.

T A B L E 3

Characteristics of the people on board and taking stool samples during a norovirus outbreak on a river-cruise sailing through Europe, 2006

\begin{tabular}{|c|c|c|c|c|c|c|}
\hline Case & Crew/passenger & Origin & NLV PCR & Onset of illness & Sample date & History of illness \\
\hline Yes & $P$ & USA & + & $30-06-2006$ & $07-07-2006$ & No \\
\hline Yes & $P$ & USA & + & $30-06-2006$ & $06-06-2006$ & No \\
\hline Yes & P & USA & + & $30-06-2006$ & $06-06-2006$ & No \\
\hline Yes & $P$ & USA & - & $03-07-2006$ & 07-07-2006 & No \\
\hline Yes & $P$ & USA & + & $03-07-2006$ & $07-07-2006$ & No \\
\hline Yes & C & Hungary & + & 03-07-2006 & 07-07-2006 & No \\
\hline Yes & $P$ & USA & + & 04-07-2006 & $06-06-2006$ & No \\
\hline No & C & Romania & - & n.a. & $06-06-2006$ & No \\
\hline No & C & Poland & - & n.a. & $06-06-2006$ & No \\
\hline No & c & Hungary & - & n.a. & $06-06-2006$ & No \\
\hline No & P & USA & - & n.a. & $06-06-2006$ & No \\
\hline No & c & Servia & - & n.a. & 07-07-2006 & No \\
\hline No & c & Romania & - & n.a. & $06-06-2006$ & No \\
\hline No & $\mathrm{c}$ & Germany & - & n.a. & $06-06-2006$ & No \\
\hline No & C & Germany & - & n.a. & $06-06-2006$ & No \\
\hline No & $P$ & USA & - & n.a. & $07-07-2006$ & No \\
\hline No & $\mathrm{P}$ & USA & - & n.a. & $06-06-2006$ & No \\
\hline
\end{tabular}


may have contributed to this and previous norovirus outbreaks on this river-cruise ship. The relative risk from water consumption became higher when combined with those who used ice cubes and drank juice, suggesting a potential dose-response relationship. The risk from water remained after correction for having a sick roommate. Moreover, the index case mentioned having consumed ice cubes during his incubation period on board the ship. Given that freezing is an excellent way to preserve viruses [14], and that the ice cubes were made with tap water, the consumption of water was a potential risk factor.

Food, water and environmental samples taken during the outbreak investigation tested positive. Unfortunately, however, these data could not be considered definitive proof due to the potential of cross-contamination. The positive water sample was taken from a tap in a room which was used by a symptomatic person. Consequently, contamination of the tap surface may have caused the contamination. To identify water as a cause of infection, water samples should be taken from the supply tank or a tap used by people free of symptoms. Similarly, the raspberries that tested positive were derived from an opened bag, since closed bags were not available for sampling. As crew members reported history of GE and the transmission through contaminated surfaces was clearly present, this may have resulted in contamination of the raspberries. Environmental swabs taken in public places on the ship tested positive. The norovirus positive handle of the ethanol-based hand sanitation bottle demonstrated that person-to-person transmission played a role despite - or even because of - prevention measures taken. This bottle was used for hand rubs just before having a meal at the buffet. Ethanol-based hands rubs may be effective in reducing bacterial infectivity, however, they may not be able to significantly reduce viral infectivity [15]. This situation illustrated the need for practical (noro)virus specific guidelines for both primary and secondary prevention of outbreaks on cruise ships.

However, for several reasons initial introduction via from water or food cannot be ruled out, and are points of concern for primary prevention measures. First, the tap water samples left a brownish colour after filtering, suggesting suboptimal quality of the water system. Water-borne outbreaks and contamination of tap water are more often described after unusual heavy rainfall [16], which also occurred in Europe at the time of the outbreaks [17]. The cruise ship had a water tank which was filled each time the ship was docked, while using the local water system (Figure 1). The tank supply was used for consumption during sailing time. It remained unclear if disinfection of the water tank was a current procedure on this ship. In general, water tanks may be a risk for infections at cruise ships [18-20], including norovirus. Second, raspberries are a well-described source of infection [21]. Unfortunately, the risk from consumption as garnish was not addressed in the questionnaire. Despite insufficient epidemiological evidence, the finding of norovirus-positive raspberries triggered a message in the European Rapid Alert System for Food and Feed (alert 2006.0546). There were no other illness reports associated with the product.

Attack rates for crew and passengers differed, with a significantly lower attack rate for crew, as has been described by others: four of five described outbreaks of GE on cruise ships in the United States in 2002 showed higher attack rates for passengers. A prospective survey on one of these ships showed $41 \%$ of the passengers suffering from GE, while $8 \%$ of passengers and $2 \%$ of crew sought medical attention [1]. Although an explanation was not given, the difference may be due to short-term immunity, which may have been acquired during successive outbreaks [22]. However, reporting bias could also play a role; underreporting by crew is imaginable in order not to worry the passengers or consequential loss of income, but was not addressed during our outbreak investigation. Although ill crew members were disembarked as a prevention measure during the previous outbreak, two new crew members were allowed on board shortly after their recovery of GE without the need for reporting their history of illness. This is a point of concern for the cruise ship industry, since person-to-person spread - directly or indirectly through food handling - is common in norovirus transmission. When returning to work, recovered employees need to be identified and thoroughly instructed to ensure personal hygiene, including food handling hygiene $[14,23]$.

Molecular analysis of viruses identified on board showed that one of the other two ships with outbreaks was contaminated with a different norovirus strain (ship B, Figure 2). On the third ship, no microbiological tests were performed for the detection of norovirus. As Figure 2 shows, strains detected on another cruise-ship (ship C) sailing through the Netherlands at that time were also distinct, although the difference was small. Interpretation of data from molecular typing needs to be undertaken with caution when no data are available about the source: in food-borne contamination events, the source of contamination is an important determinant. In food-handler associated outbreaks, typically a single strain is found and finding dissimilar sequences is supportive evidence. However, when contamination occurs higher in the food chain, e.g. during irrigation, multiple strains may be present and finding dissimilar sequences does not necessarily disprove a causal link. Only thorough outbreak investigations that include product tracing can provide definitive evidence, but this is often considered to be too complicated $[24,25]$.

Cruise ships are highly susceptible to norovirus outbreaks $[2,26]$. Once the virus is introduced in this closed setting, personto-person transmission plays an important role [27]. If the virus is not eliminated - either through identification of a point source, disinfection of the environment or disembarkation of shedding crew - a successive outbreak at a cruise ship is likely to occur as a consequence of a group of new and susceptible people entering the ship [28]. Therefore, the detection of point sources and the immediate implementation of accurate cleaning measures during the initial outbreak are necessary for the prevention of new outbreaks on successive trips. As cruise ships usually sail through several countries, international guidelines for reporting, investigating and controlling norovirus outbreaks on cruise ships are needed [29]. Such guidelines need to be practicable for cruise staff, since an outbreak investigation team will mostly be present when person-to-person transmission cannot be separated from a potential point source introduction [4]. Since July, 2007, guidance for the management of cruise ships in the United Kingdom has been available online, which is a first step towards European outbreak control: http://www.hpa.org.uk/publications/2007/cruiseliners/ cruiseliners.pdf. 


\section{Acknowledgements}

We are grateful to the involved cruise ship's crew, for their approval for this study and their kind cooperation in data-collection. We thank Evelyn Depoortere for initiating this investigation and René Koenen for giving us the opportunity to perform the study. We would also like to thank Yvonne van Duynhoven and Annelies Kroneman for their support during the preparation of the study on short notice.

We would also like to express our gratitude for the contribution of the following: Michel Heijneman, who took environmental, food and water samples during the onsite investigation; Nathalie te Loeke, who was involved in analysing all environmental swab and food samples for the presence of norovirus; Bas van der veer, who performed laboratory testing of all stool samples; Willemijn Lodder for the analysis of water samples and ice cubes; Soizick LeGuyader, Leena Maunula and Froukje Lodder-Verschoor who analysed the sampled raspberries for presence of norovirus.

\section{References}

1. Outbreaks of gastroenteritis associated with noroviruses on cruise shipsUnited States, 2002. MMWR Morb Mortal Wkly Rep 2002; 51(49):1112-1115.

2. Widdowson MA, Cramer EH, Hadley L, Bresee JS, Beard RS, Bulens SN et al. Outbreaks of acute gastroenteritis on cruise ships and on land: identification of a predominant circulating strain of norovirus--United States, 2002. J Infect Dis 2004; 190(1):27-36.

3. Isakbaeva ET, Widdowson MA, Beard RS, Bulens SN, Mullins J, Monroe SS et al. Norovirus transmission on cruise ship. Emerg Infect Dis 2005; 11(1):154158.

4. Verhoef L, depoortere E, Boxman I, Duizer E, van Duynhoven Y, Harris J et al. Emergence of New Norovirus Variants on Spring Cruise Ships and Prediction of Winter Epidemics. Emerg Infect Dis 2008; 14(2):238-243.

5. Koopmans M, Harris J, Verhoef L, Depoortere E, Takkinen J, Coulombier D. European investigation into recent norovirus outbreaks on cruise ships: update. Euro Surveill 2006; 11(7):E060706.

6. Takkinen J. Recent norovirus outbreaks on river and seagoing cruise ships in Europe. Euro Surveill 2006; 11(6):E060615.

7. Jones TF, Bulens SN, Gettner S, Garman RL, Vugia DJ, Blythe D et al. Use of stool collection kits delivered to patients can improve confirmation of etiology in foodborne disease outbreaks. Clin Infect Dis 2004; 39(10):1454-9.

8. Duizer E, Pielaat A, Vennema H, Kroneman A, Koopmans M. Probabilities in norovirus outbreak diagnosis. J Clin Virol 2007.

9. Svraka S, Duizer E, Vennema H, de Bruin E, van der Veer B, Dorresteijn B et al. Etiological role of viruses in outbreaks of acute gastroenteritis in The Netherlands from 1994 through 2005. J Clin Microbiol 2007; 45(5):1389-1394.

10. Vinje J, Vennema H, Maunula L, von Bonsdorff $\mathrm{CH}$, Hoehne M, Schreier E et al. International collaborative study to compare reverse transcriptase PCR assays for detection and genotyping of noroviruses. J Clin Microbiol 2003; 41(4):1423-1433.

11. Boxman IL, Tilburg JJ, te Loeke NA, Vennema H, Jonker $K$, de Boer $E$ et al. Detection of noroviruses in shellfish in the Netherlands. Int J Food Microbiol 2006; 108(3):391-396.

12. Boxman IL, Tilburg JJ, te Loeke NA, Vennema H, de Boer E, Koopmans M. An efficient and rapid method for recovery of norovirus from food associated with outbreaks of gastroenteritis. J Food Prot 2007; 70(2):504-508.

13. Van den Berg H., Lodder W, van der PW, Vennema H, Roda Husman AM. Genetic diversity of noroviruses in raw and treated sewage water. Res Microbiol 2005; 156(4):532-540.

14. Koopmans M, Duizer E. Foodborne viruses: an emerging problem. Int J Food Microbiol 2004; 90(1):23-41.

15. Sattar SA, Springthorpe VS, Tetro J, Vashon R, Keswick B. Hygienic hand antiseptics: should they not have activity and label claims against viruses? Am J Infect Control 2002; 30(6):355-372.

16. Hrudey SE, Hrudey EJ. Published case studies of waterborne disease outbreaks -evidence of a recurrent threat. Water Environ Res 2007; 79(3):233-245.

17. Krisztalovics K, Reuter G, Szucs G, Csohan A, Borocz K. Increase in norovirus circulation in Hungary in October-November 2006. Euro Surveill 2006; 11(12):E061214

18. Daniels NA, Neimann J, Karpati A, Parashar UD, Greene KD, Wells JG et al. Traveler's diarrhea at sea: three outbreaks of waterborne enterotoxigenic Escherichia coli on cruise ships. J Infect Dis 2000; 181(4):1491-1495.
19. Khan AS, Moe CL, Glass RI, Monroe SS, Estes MK, Chapman LE et al. Norwalk virus-associated gastroenteritis traced to ice consumption aboard a cruise ship in Hawaii: comparison and application of molecular method-based assays. J Clin Microbiol 1994; 32(2):318-322.

20. Regan CM, McCann B, Syed Q, Christie P, Joseph C, Colligan J et al. Outbreak of Legionnaires' disease on a cruise ship: lessons for international surveillance and control. Commun Dis Public Health 2003; 6(2):152-156.

21. Falkenhorst G, Krusell L, Lisby M, Madsen SB, Bottiger B, Molbak K. Imported frozen raspberries cause a series of norovirus outbreaks in Denmark, 2005. Euro Surveill 2005; 10(9):E050922.

22. Lindesmith L, Moe C, Marionneau S, Ruvoen N, Jiang X, Lindblad L et al. Human susceptibility and resistance to Norwalk virus infection. Nat Med 2003 $9(5): 548-553$.

23. Cowden JM, Wall PG, Adak G, Evans H, Le Baigue S, Ross D. Outbreaks of foodborne infectious intestinal disease in England and Wales 1992 and 1993. CDR Rev 1995; 5:R109-R117-17.

24. Gallimore CI, Pipkin C, Shrimpton H, Green AD, Pickford Y, McCartney C et al. Detection of multiple enteric virus strains within a foodborne outbreak of gastroenteritis: an indication of the source of contamination. Epidemiol Infect 2005;(1):41-7.

25. Le Guyader FS, Bon F, DeMedici D, Parnaudeau S, Bertone A, Crudeli S et al. Detection of multiple noroviruses associated with an international gastroenteritis outbreak linked to oyster consumption. Journal of Clinical Microbiology 2006; 44(11):3878-82.

26. Centers for Disease Control and Prevention. Vessel Sanitation Program Operations Manual 2000. 2000. Atlanta, US Department of Health and Human Services.

27. Lopman BA, Adak GK, Reacher MH, Brown DW. Two epidemiologic patterns of norovirus outbreaks: surveillance in England and wales, 1992-2000. Emerg Infect Dis 2003; 9(1):71-77.

28. Parashar U, Quiroz ES, Mounts AW, Monroe SS, Fankhauser RL, Ando T et al. "Norwalk-like viruses". Public health consequences and outbreak management. MMWR Recomm Rep 2001; 50(RR-9):1-17.

29. Depoortere E, Takkinen J. Coordinated European actions to prevent and control norovirus outbreaks on cruise ships. Euro Surveill 2006; 11(10):E061018.2. Available from: http://www.eurosurveillance.org/ew/2006/061018.asp\#2.

This article was published on 12 June 2008

Citation style for this article: Verhoef L, Boxman I, Duizer E, Rutjes SA, Vennema H, Friesema IH, de Roda Husman AM, Koopmans M. Multiple exposures during a norovirus outbreak on a river-cruise sailing through Europe, 2006. Euro Surveill. 2008:13(24):pii=18899. Available online: http://www.eurosurveillance.org/ViewArticle. aspx?ArticleId=18899 